\title{
REMISSION OF BENIGN EPILEPSY WITH ROLANDIC SPIKES: AN EEG-BASED CONNECTIVITY STUDY AT THE ONSET OF THE DISEASE AND AT REMISSION
}

${ }^{1}$ Clemens B., MD, PhD; ${ }^{2}$ Puskás S., MD, PhD; ${ }^{3}$ Besenyei M., MD;. ${ }^{4}$ Spisák T.; ${ }^{4}$ Emri M PhD., ${ }^{2}$ Fekete I., MD, PhD.

\footnotetext{
${ }^{1}$ Kenézy Hospital Ltd., Department of Neurology, Bartók Béla út 3., 4031 Debrecen, Hungary

${ }^{2}$ University of Debrecen, Medical and Health Science Center, Department of Neurology, Móricz Zsigmond krt. 22., 4032 Debrecen, Hungary

${ }^{3}$ University of Debrecen, Medical and Health Science Center, Department of Pediatrics, Nagyerdei krt. 98., 4012 Debrecen, Hungary

${ }^{4}$ University of Debrecen, Institute of Nuclear Medicine, Nagyerdei krt. 98., 4012 Debrecen, Hungary
}

Corresponding author: Szilvia Puskás, MD, PhD.

University of Debrecen, Medical and Health Science Center, Department of Neurology

Móricz Zsigmond krt. 22

4032 Debrecen

Hungary

TEL: ++36 52255341

Fax: ++36 52453590

E-mail: szilvia.puskas@yahoo.com 


\section{Abstract}

Purpose. The neuronal mechanisms of remission of epilepsy are not known. Based on the principles of the "network theory of epilepsy" we postulated the existence of abnormal cortico-cortical interactions at the onset of epilepsy (Hypothesis-1), and postulated that remission is associated with the decrease or disappearance of the abnormal quantitative EEG findings (Hypothesis-2).

Methods. Four children with benign epilepsy with rolandic sharp waves (BERS) were investigated. 21-channel EEG was recorded at the onset of the disease (Setting No.1) and in remission (Setting No.2). Local EEG synchronization was estimated by LORETA (Low Resolution Electromagnetic Tomography). Remote EEG synchronization (intra-hemispheric, cortico-cortical EEG functional connectivity, EEGfC) was computed by the LSC (LORETA Source Correlation) method, among 23 regions of interest $(\mathrm{ROI})$ in both hemispheres. Both local and remote EEG synchronization were evaluated in very narrow frequency bands of $1 \mathrm{~Hz}$ bandwidth (VNB), from 1 to $25 \mathrm{~Hz}$.

Results. Individual results were presented. Abnormal but topographically very dissimilar LORETA and LSC findings were found at the onset of the disease. The disappearance of the initial abnormalities was found in Setting No.2. An unforeseen finding was the presence of abnormal EEGfC results in Setting No.2.

Discussion. The authors confirmed both hypotheses. The dissimilarity of the initial abnormalities is in accord with the network concept of epilepsy and the etiology of BERS. The disappearance of the initial abnormalities reflects "normalization" of network dynamics while the emergence of new EEGfC abnormalities is interpreted as "compensation".

Conclusion. EEG-based local and remote connectivity (EEGfC) are appropriate tools to describe network dynamics in the active state of BERS and in remission.

Key words: epilepsy, remission, EEG, network theory, LORETA, LORETA Source Correlation 


\section{Introduction}

Epilepsy affects about 0.5-1 per cent of the human population. It impairs the quality of life of the patients and significantly contributes to the costs of the healthcare system (Strzelczyk et al., 2008). Therefore, maximal research efforts are desired to mitigate the burden of epilepsy in all respects. Unfortunately, this is not the case. Leading experts criticize unimaginative research strategies that cannot exceed the old concepts of treating epilepsy and drug development (Löscher and Schmidt, 2011). In fact, the patients are treated with drugs that prevent seizures in the responders but do not influence the basic, long-lasting CNS processes that are responsible for the seizure-prone state of the brain. An alternative way of thinking and research may start with realizing that all sorts of epilepsy are dynamic disorders. The epileptic brain may be characterized by abnormal network activities at large spatial scales (Bragin et al., 2000; Schevon et al., 2007; Spencer, 2002; Ponten et al., 2007;

Horstmann et al., 2009). However, epilepsy is neither steady nor irreversible. The fluctuating course of epilepsy (Sillanpää and Schmidt, 2006), the decrease of seizure propensity with age (Wolf et al., 2006) and the remission of about 50 per cent of the patients with untreated epilepsy (Sander and Sillanpää, 1997) strongly argues for the existence of natural mechanisms that can mitigate and even stop epilepsy at all ages. However, the neuronal basis of remission has never been investigated.

We intended to investigate this issue in benign childhood epilepsy with rolandic sharp waves (BERS). We postulated that the remission of epilepsy in BERS is due to adaptive network modification by nature. If so, EEG recorded at the onset of the disease reflects the abnormal, ictogenic state of a yet not specified cerebral network (Hypothesis-1), while EEG recorded in remission reflects the normalized connectivity state of the network that has lost its ictogenic property (Hypothesis-2). Given the dominant role of the cortex in ictogenesis (Timofeev and Steriade, 2004), we limited this study to cortico-cortical interactions.

\section{Patients and methods}

Newly diagnosed patients with BERS were enrolled. Inclusion criteria were: a correct diagnosis according to the clinical and EEG criteria of BERS (Dalla Bernardina et al., 2002), no comorbidity; a baseline waking EEG of good technical quality recorded at the first visit, in the drug-free state (EEG1). Cranial MRI was carried out in all the BERS patients. The eligible children were treated and followed as usual in our practice. Antiepileptic treatment was prescribed by the child neurologist. Treatment resulted in complete seizure freedom in all the cases. After a few seizure-free years the child neurologist decided gradual withdrawal of the drug. EEG2 was recorded three months after drug discontinuation. The seizures did not recur in the follow-up period of 2 years after drug discontinuation. The patients' data are summarized in Table 1. The study design was approved by the Local Research Ethics Committee of Kenézy Kórház Ltd. No diagnostic procedure or treatment was indicated, missed or postponed for study purposes. The research data were managed and stored using identification numbers.

\footnotetext{
Abbreviations: BERS - benign epilepsy with rolandic sharp waves; EEGfC - EEG functional connectivity; LORETA - Low Resolution Electromagnetic Tomography; LSC - LORETA Source Correlation; R - Pearson correlation coefficient; $\mathrm{ROI}$ - region of interest; VNB - very narrow band
} 


\subsection{EEG recording and epoch selection}

EEG recordings were carried out in the morning, in a semi-isolated room, with the same type of digital equipment, by trained personnel, according to recommended standards for quantitative EEG studies (Nuwer et al., 1994). Silver-silver chloride electrodes were placed according to the 19 sites of the 1020 System and the earlobes, fixed by appropriate adhesive and conductive gel. Impedances did not exceed $10 \mathrm{kOhm}$. EEG was recorded against Fpz sampling reference, and recomputed against a mathematical linked ears reference. Additional bipolar derivations were used to differentiate between EEG and eye movement potentials and to detect myogenic activity. For EEG, the filters were set at 0.1 and $33.6 \mathrm{~Hz}$. Sampling frequency was 128 per second, on-line digitization was 12 bit. 30 minutes EEG was recorded in the waking-relaxed, eyes-closed condition. The state of vigilance was controlled by the EEG technician who gently aroused the patient when the posterior alpha rhythm disappeared. Two-second epochs were selected according to our standard epoch selection protocol: 1. the presence of continuous alpha activity with voltage maximum in posterior regions; 2 . the absence of artifacts, epileptiform potentials, and other nonstationary elements; 3 . the absence of patterns indicating drowsiness or arousal. Epochs selected in this way correspond to a narrow range of vigilance (Bente, 1979). Two reproducibility measures were used to minimize the effect of short- and long-term variability within the sample. Split-half reliabilty is the variance of between the even and odd seconds of the time series of the selected EEG sample. Test-retest reliability is the ratio of variance between the first half versus the second half of the selected EEG segments. High reliability measures ensure that very similar EEG epochs were selected for analysis. In other words, this means that contamination of the analyzed EEG epochs with non-stationaly elements and vigilance-related shifts are minimized. Only samples with at least 95 percent of average split-half reliability and test-retest reliability (across the 19 channels) entered further analysis.

\subsection{Quantitative EEG analyses}

Ninety, 2-seconds epochs were processed to the NeuroGuide 2.7.4. software and the linked Low Resolution Electromagnetic Tomography, and the LORETA Source Correlation softwares. Instead of space-consuming descripiton of these methods only some basics and the rationale of chosing these analysis methods are summarized here. For details, basic papers (Pascual-Marqui et al., 1994; Pascual-Marqui, 2002; Thatcher et al., 2007) and a website containing comprehensive description of the methods are recommended (www.appliedneuroscience.com). In this paper, LORETA1 and LSC1 refer to the initial EEG record (EEG1) while LORETA2 and LSC2 findings result from the analysis of EEG2, recorded in remission.

LORETA is a source localization method that demonstrates multiple distributed sources of EEG activity in the three-dimensional space. It computes current source density, ampers/meters squared (briefly, "activity") in very narrow frequency bands of $1 \mathrm{~Hz}$ bandwidth, for 2394 voxels that represent the cortical gray matter including the hippocampi. LORETA superimposes the age-adjusted, Z-scored and color-coded activity values on magnetic resonance imaging figures of a standard brain atlas, using the Talairach coordinates (Talairach and Tournoux, 1988). The goal of LORETA analysis was to demonstrate abnormal local EEG synchronization in the 1-25 Hz frequency range. In this paper "local" refers to synchronized EEG activity within a cortical area. In epilepsy, abnormally synchronization rapidly spreads across a lot of cortical columns and even greater cortical areas via the dense network of short intracortical connections (Chagnac-Amitai and Connors, 1989) of about 1 to 5 millimeters length (Braitenberg, 1978). Abnormally synchronized EEG background activity does not respect anatomical borders and shows smooth gradients of the electric field as demonstrated by 
intracranial EEG (Schevon et al., 2007). Cross-modal validations and simulation studies showed that LORETA localization shows good correspondence with the reference imaging methods in these circumstances (Pascual-Marqui, 1999, 2002; Oakes et al., 2004). Based on these findings, in this study we report LORETA localization with the precision of specifying the gyri where the maximum abnormality occurs. As to neurobiological interpretation, EEG and LORETA reflect genetically determined, age-dependent cerebral processes (Zietsch et al., 2007). The sum of these processes is frequently called "brain maturation" by pediatric neurologists. LORETA results are of very good reliability in the run of 30 days (Cannon et al., 2012).

LSC analysis means to compute the temporal covariance or correlation of LORETA current source density between two cortical areas, across successive 2-second epochs over the investigated sample. The results are called EEG functional connectivity and should be interpreted in the general frameworks of cerebral connectivity (Stam and van Straaten, 2012) and functional connectivity (Friston, 2011). Computing Pearson correlation coefficients is a robust method being sensitive to all the investigated coupling parameters and does not require specific assumptions about the model (Wendling et al., 2009). In this study we followed the design described in a pioneering LSC study (Thatcher et al., 2007). Given the 19 scalp electrodes, the effects of the point spread on current density estimates was minimized by clustering hundreds of nearby voxels into 23 regions of interest in each hemisphere. $R$ values were age-adjusted and Z-transformed. The computation flowchart (Fig. 1) explains that the correlation between ROla and ROlb is not necesserily equal to that between ROlb and ROla. As to overcome this ambiguity we calculated the average of the two $R$ values. The topographical EEGfC patterns were visualized by a software developed at the Institute of Nuclear Medicine, University of Debrecen (www.minipetct.com/braincon). The rationale for investigating LSC was to evaluate remote, intra-hemispheric cortico-cortical EEGfC among ROls that are anatomically connected by short and long association fibers (Braitenberg, 1978). Like LORETA, LSC was computed for $1 \mathrm{~Hz}$ VNBs, from 1 to $25 \mathrm{~Hz}$. EEGfC is genetically determined (Smit et al., 2008). It is a real measure of connectivity of the developing brain although the relationship between functional and anatomical connectivity is far from understood (Friston, 2011).

The Z-score reflects the degree of deviation of an individual value from the normative mean $(Z=0)$ of the corresponding age group. $Z$-scored quantitative $E E G$ variables are independent of race, sex and geographical location (John et al., 1983). Descriptions of the LORETA and LSC normative databases are to be found at the website (www.appliedneuroscience.com). Given that the voxel-wise results are not independent, correction for multiple comparisons was done according to (Grave de Peralta Menendez et al., 2004). So the corrected $p=0.05$ values corresponded to $Z= \pm 3.0$. Statistical interpretation of the $Z$-score means that values outside the $Z= \pm 3$ range are abnormal with 99 per cent probability. For the sake of brevity, henceforth $Z>3$ and and $Z<-3$ values will be labelled as "abnormal", or "increased" and "decreased", as compared to the normative mean. The term "normal" refers to $Z$-values within the $Z= \pm 3$ range.

\section{Results}

The results are summarized in Table 2. At the onset of the disease, all but one patients had abnormal LORETA1 findings and all the patients had abnormal LSC1 findings. Each patient displayed an individual combination of LORETA1 and LSC1 abnormalities. These individual patterns were very dissimilar regarding the number of the abnormal scores, their topographical distribution, the affected VNBs and the sign of the abnormalities (increased and/or decreased). Some degree of LORETA1LSC1 topographical correspondence was found in three patients. This means that a cortical area with 
abnormal LORETA score overlaps with a ROI that shows abnormal EEGfC with one or more other ROls. However, topographical overlap was not associated with shared VNBs. Two examples are given in Fig 2.

In the three patients with abnormal LORETA1 scores, remission was associated with normal LORETA2 findings (LORETA normalization). Pt 4. with no abnormal LORETA1 and LORETA2 findings was not interpretable in this respect. Normal LSC2 scores were found in Pt 2. while the remaining three patients showed re-arrangement of the LSC abnormalities. This means that the LSC1 abnormalities (each defined by its topography, sign, and the affected VNB) disappeared but other abnormalities emerged in the LSC2 setting. Some of the LSC1 abnormalities topographically persisted in the LSC2 pattern but wandered to another VNB. An example for the complex relationship between the LSC1 and LSC2 patterns is given in Fig 3.

\section{Discussion}

As far as is known, this is the first attempt to investigate the neuronal mechanisms of remission within the framework of the network theory of epilepsy. The network theory was originally based on neurophysiological argumentation (Spencer, 2002). However, the idea that focal cerebral manifestations and/ or epilepsy are associated with topographically distributed abnormal network dynamics has been supported by graph analysis of EEG, magnetoencephalographic and functional MRI data and simulation studies as well (Bartolomei et al., 2006; Bettus et al., 2008; Alstott et al., 2009; Lehnertz et al., 2009). Also treatment-related changes of magnetoencephalographic functional connectivity were reported (Douw et al., 2008). These results support that computing EEGfC may be a useful method to characterize and compare dissimilar states in epilepsy, including the active state of the disease and remission.

\subsection{Quantitative EEG abnormalities in the active state of the disease}

We confirmed Hypothesis-1 insofar as the active phase of BERS was characterized by abnormal local connectivity (LORETA1 findings) in all but one patients and abnormal remote EEGfC (LSC1 findings) in all the patients. The lack of LORETA1 abnormalities in the remaining one patient may be interpreted as the limitation of defining the abnormality on the statistical basis.

With a few exceptions, all the abnormalities were inside the $Z= \pm 4$ range. Mild but clinically evident cerebral dysfunction is associated with topographically widespread quantitative EEG abnormalities scored about $Z=4$ to 5 in idiopathic epilepsy (Clemens, 2004). Thus it seems that the present results correspond to an even milder cerebral abnormality. In fact, most children with BERS (including our patients) do not present with clinically evident neurological and mental deficit symptoms (Dalla Bernardina et al., 2002).

One might suppose that the LORETA1 and LSC1 findings may topographically correspond to the cortical areas that are known to be dysfunctional in BERS. The sharp wave-generator central area (Pataraia et al., 2008) and a temporo-parietal area showing abnormal EEG background activity (Besenyei et al., 2012) are areas of interest in this respect. Our LORETA1 and LSC1 findings did not show conclusive topographical overlap with these areas. Furthermore, we found variable degree of topographical LORETA1-LSC1 correspondence. Our findings suggest that the cortical compartment of the "BERS network" is not an invariable set of cortical areas and interconnections. Instead, the great variability of the LORETA1 and LSC1 findings indicate great variability of the individual network abnormalities. The diversity of our findings is in accord with a lot of papers reporting poor 
topographical correspondence between localized pathology or epileptic dysfunction and diffusely distributed, abnormal, resting-state network dynamics (Bartolomei et al., 2006; Bettus et al., 2008; Alstott et al., 2009; Lehnertz et al., 2009).

Another source of the dissimilar findings might be the dissimilar topographical distribution of the underlying pathological process. The pathological basis of BERS has not been exactly specified, but seems to be associated with abnormal brain connectivity and seizure liability. However, which parts of the brain show faulty organization in BERS and related conditions is not clear. Besides the already mentioned dysfunctional areas (Pataraia et al., 2008; Besenyei et al., 2012), the diversity of the neuropsychological deficits (Chahine and Mikati, 2006; Kavros et al., 2008; Smith et al., 2012) and the great percentage of atypical BERS cases (Wirrel et al., 1995) argue for the incorporation of further cortical areas into the "individual BERS network".

To what degree the sharp waves contribute to abnormal EEGfC in the active state of the disease is not clear. Interictal spikes may aggravate abnormal functional MRI connectivity in epileptic patients (Mankinen et al., 2012). Albeit we excluded epochs with sharp waves from analysis, delayed effects of the sharp waves on EEG background activity (Clemens et al., 2009) cannot be excluded. Sharp waves generated within small cortical areas are not detectable by scalp EEG (Tao et al., 2007) but may alter EEG dynamics. Furthermore, we are going to learn that "EEG background activity without epileptiform events" is perhaps a fiction at the submillimeter scale (Schevon et al., 2010). In any case, the patient with most frequent and bilateral sharp waves ( $\mathrm{Pt}$ 3.) presented with the greatest number of abnormal quantitative EEG findings.

\subsection{Quantitative EEG abnormalities in remission}

We also confirmed Hypothesis-2. Remission was characterized by the disappearance of the abnormal quantitative EEG findings that had been found in the active state of the disease. In other words, this means normalization of abnormal, cortico-cortical network dynamics of the brain. Discussing the causes of LORETA and LSC normalization is beyond the scope of this paper. Age-dependent turning off of abnormal gene activity may be an evident solution, consistent with the self-limiting nature of BERS, the lack of the sharp waves in EEG2 and the reported shifts of the initially abnormal quantitative EEG scores towards zero.

Remote EEGfC (LSC2 findings) showed more complex changes as compared to the initial condition. New, abnormal findings emerged that were inconsistently related to the LSC1 findings in terms of topography, VNB and sign. We interpreted these results as "compensatory", reflecting the self-repairing power of the brain, a complex system (Buzsáki, 2006). Based on its strong genetic determination, LSC is known to reflect brain maturation. However, brain maturation is not simply the translation of definite genetic information into brain structure and connectivity. It includes the capacity to maintain homeostasis at the network level in the face of destabilizing forces (Turrigiano and Nelson, 2004; Marder and Goaillard, 2006). In fact, compensatory network changes were demonstrated in a functional MRI study of childhood epilepsy (Mankinen et al., 2012). As to the dissimilarity of the LSC2 findings, a scenario where the compensatory changes are restricted to a single cortical area or connection would be naive. Homeostatic plasticity may affect multiple neuronal mechanisms. The reported LSC2 abnormalities presumably reflect the multiplicity and redundancy of functional compensatory actions of the brain that was demonstrated in EEG recordings (De Vico Fallani et al., 2011). If so, statistically abnormal findings may be interpreted as being adaptive or, compensatory in the neurophysiological sense.

The possible role of antiepileptic drugs in network normalization should be mentioned here. As far as is known, the role of the these drugs on long-term network re-arrangement has never been 
investigated. Thus we cannot rule out the possibility that drug treatment contributed to the long-term changes of the LORETA and LSC abnormalities in our patients.

We hope that this pilot study will encourage further research in this area. Issues of potential interest are: the relevance of our findings to other epilepsy syndromes; the organization of intermediary states of altered connectivity between the initial state and remission; the effects of lesions, seizures and medication on cerebral connectivity. A lot of further investigations are necessary to get some insight into connectivity changes associated with mitigating the severity of epilepsy and remission. A presently far but fascinating perspective is that if we get acquainted with the neuronalnetwork mechanisms of remission, pharmacological or surgical modification of them might be new strategies of true anti-epileptic treatment (Duffau, 2006).

\subsection{Limitations of the study}

The analysis of four BERS cases is not sufficient to draw final conclusions. In this pilot study we only demonstrated that long-term network changes occur in all the investigated patients. We hope that this finding may facilitate further research in this, yet neglected direction.

Disregarding $>25 \mathrm{~Hz}$ frequencies is another limitation. This was partly due to low sampling rate used in routine EEG recordings. The role of gamma and even faster rhythms in epilepsy have been suggested recently. On the other hand, we consciously focused on slower frequencies because graph analyses (a lot of mathematically appropriate tools to investigate biological networks) strongly suggest that cerebral networks derived from low frequency data are more intimately related to structural connectivity than those computed at higher frequencies (Honey et al., 2007).

As pointed out in the Introduction, intra-hemispheric interactions are presumably the most important network events resulting in ictogenicity. However, the complete scenario also includes interhemispheric network actions, which had not been addressed in this study because of software limitations.

\section{Conclusions}

EEG-based local and remote connectivity (EEGfC) are appropriate tools to describe network dynamics in the active state of BERS and in remission. The disappearance of the initial abnormalities reflects "normalization" of network dynamics while the emergence of new EEGfC abnormalities is interpreted as "compensation".

\section{Appendices}

Fig 1. The flowchart of computing LORETA Source Correlation (after Thatcher et al, 2007., slightly modified. With permission of the author).

Fig 2. Correlation of the LORETA1 and LSC1 abnormalities in two patients. 2A: decreased LORETA activity in the left inferior frontal gyrus (blue color), decreased EEG functional connectivity between the left inferior frontal gyrus and the parahippocampal gyrus and uncus (blue color). 2B: increased LORETA activity in the left and right lateral temporal gyri and the insulae (red color); maximum score in the right superior temporal gyrus. Only VNBs with at least 3 abnormal connections are demonstrated in Fig. 2B. Both patients present with some degree of topographical LORETA-LSC 
correspondence (disregarding the VNB where the abnormal findings emerged). Red dots indicate the geometrical centroid of the ROls.

Fig 3. Correlation of the LSC1 and LSC2 abnormalities in Pt 3. Left column: LSC1 findings, right column: LSC2 findings. The VNBs are given in the plots. The LSC2 pattern shows normalization (disappearance of the mainly right hemispheric LSC1 abnormalities) and suggest compensation (de novo emergence of multiple, mainly bilateral abnormalities).

\section{References}

Alstott, J., Breakspear, M., Hagmann, P., Cammoun, L., Sporns, O. (2009). Modeling the impact of lesions in the human brain. PLoS Comput Biol, 5, e1000408.

Bartolomei, F., Bosma, I., Klein, M., Baayen, J. C., Reijneveld, J. C., Postma, T. J., Heimans, J. J., van Dijk, B. W., de Munck, J. C., de Jongh, A., Cover, K. S., Stam, C. J. (2006). How do brain tumors alter functional connectivity? A magnetoencephalography study. Ann Neurol, 59, 128-138.

Bente, D. (1979). Vigilance and evaluation of psychotropic drug effect on EEG. Pharmacopsychiatry, $12,137-147$.

Besenyei, M., Varga, E., Fekete, I., Puskás, S., Hollódy, K., Fogarasi, A., Emri, M., Opposits, G., Kis, S. A., Clemens, B. (2012). EEG background activity is abnormal in the temporal and inferior parietal cortex in benign rolandic epilepsy of childhood: a LORETA study. Epilepsy Res, 98, 44-49.

Bettus, G., Wendling, F., Guye, M., Valton, L., Régis, J., Chauvel, P., Bartolomei, F. (2008). Enhanced EEG functional connectivity in mesial temporal lobe epilepsy. Epilepsy Res, 81, 58-68.

Bragin, A., Wilson, C. L., Engel, J. Jr. (2000). Chronic epileptogenesis requires development of a network of pathologically interconnected neuron clusters: a hypothesis. Epilepsia, 41 Suppl 6 , S144-152.

Braitenberg, V. (1978). Cortical architectonics: general and areal. In M.A.B. Brazier, \& H. Petsche (Eds.), Architectonics of the cerebral cortex (pp.443-465). New York: Raven Press.

Buzsáki, G. (2006). Coupling of systems by oscillations. In G. Buzsáki (Editor), Rhythms of the Brain (pp. 334-356). New York: Oxford University Press.

Cannon, R. L., Baldwin, D. R., Shaw, T. L., Diloreto, D. J., Phillips, S. M., Scruggs, A. M., Riehl, T. C. (2012). Reliability of quantitative EEG (qEEG) measures and LORETA current source density at 30 days. Neurosci Lett, 518, 27-31.

Chagnac-Amitai, Y., Connors, B. W. (1989). Horizontal spread of synchronized activity in neocortex and its control by GABA-mediated inhibition. J Neurophysiol, 61, 747-758.

Chahine, L. M., Mikati, M. A. (2006). Benign pediatric localization-related epilepsies. Part II. Syndromes in childhood. Epileptic Disorder, 8, 243-258. 
Clemens, B. (2004). Abnormal quantitative EEG scores identify patients with complicated idiopathic generalised epilepsy. Seizure, 13, 366-374.

Clemens, B., Piros, P., Bessenyei, M., Varga, E., Puskas, S., Fekete, I. (2009). The electrophysiological "delayed effect" of focal interictal epileptiform discharges. A low resolution electromagnetic tomography (LORETA) study. Epilepsy Res, 85, 270-278.

Dalla Bernardina, B., Sgro, V., Fejerman, N. (2002). Epilepsy with centro-temporal spikes and related syndromes. In J. Roger, M. Bureau, Ch. Dravet, P. Genton, C.A. Tassinari, P. Wolf (Eds.), Epileptic syndromes in infancy, childhood and adolescence (pp. 181-202.). UK: John Libbey \& Co.

De Vico Fallani, F., Rodrigues, F. A., da Fontoura Costa, L., Astolfi, L., Cincotti, F., Mattia, D., Salinari, S., Babiloni, F. (2011). Multiple pathways analysis of brain functional networks from EEG signals: an application to real data. Brain Topogr, 23, 344-354.

Douw, L., Baayen, H., Bosma, I., Klein, M., Vandertop, P., Heimans, J., Stam, K., de Munck, J., Reijneveld, J. (2008). Treatment-related changes in functional connectivity in brain tumor patients: a magnetoencephalography study. Exp Neurol, 212, 285-290.

Duffau, H. (2006). Brain plasticity: from pathophysiological mechanisms to therapeutic applications. $J$ Clin Neurosci, 13, 885-897.

Friston, K. J. (2011). Functional and effective connectivity: a review. Brain Connect, 1, 13-36.

Grave de Peralta Menendez, R., Murray, M. M., Michel, C. M., Martuzzi, R., Gonzalez Andino, S. L. (2004). Electrical neuroimaging based on biophysical constraints. Neuroimage, 21, 527-539.

Honey, C. J., Kötter, R., Breakspear, M., Sporns, O. (2007). Network structure of cerebral cortex shapes functional connectivity on multiple time scales. PNAS, 104, 10240-10245.

Horstmann, M. T., Bialonski, S., Noennig, N., Mai, H., Prusseit, J., Wellmer, J., Hinrichs, H., Lehnertz, K. (2009). State dependent properties of epileptic brain networks: comparative graph-theoretical analyses of simultaneously recorded EEG and MEG. Clin Neurophysiol, 121, 172-185.

John, E. R., Prichep, L., Ahn, H., Easton, P., Fridman, J., Kaye, H. (1983). Neurometric evaluation of cognitive dysfunctions and neurological disorders in children. Progress Neurobiol, 21, 329-290.

Kavros, P. M., Clarke, T., Strug, L. J., Halperin, J. M., Dorta, N. J., Pal, D. K. (2008). Attention impairment in rolandic epilepsy: systematic review. Epilepsia, 49, 1570-1580.

Lehnertz, K., Bialonski, S., Horstmann, M. T., Krug, D., Rothkegel, A., Staniek, M., Wagner, T. (2009). Synchronization phenomena in human epileptic brain networks. J Neurosci Methods, 183, 42-48.

Löscher, W., Schmidt, D. (2011). Modern antiepileptic drug development has failed to deliver: ways out of the current dilemma. Epilepsia, 52, 657-678. 
Mankinen, K., Jalovaara, P., Paakki, J. J., Harila, M., Rytky, S., Tervonen, O., Nikkinen, J., Starck, T., Remes, J., Rantala, H., Kiviniemi, V. (2012). Connectivity disruptions in resting-state functional brain networks in children with temporal lobe epilepsy. Epilepsy Res, 100, 168-178.

Marder, E., Goaillard, J. M. (2006). Variability, compensation and homeostasis in neuron and network function. Nat Rev Neurosci, 7, 563-574.

Nuwer, M., Lehmann, D., Lopes da Silva, F., Matsuoka, S., Sutherling, W., Vibert, J.F. (1994). IFCN guidelines for topographic and frequency analysis of EEGs and EPs. Report of an IFCN committee. Electroenceph Clin Neurophysiol, 91, 1-5.

Oakes, T. R., Pizzagalli, D. A., Hendrick, A. M., Horras, K. A., Larson, C. L., Abercrombie, H. C., Schaefer, S. M., Koger, J. V., Davidson, R. J. (2004). Functional coupling of simultaneuos electrical and metabolic activity in the human brain. Hum Brain Mapp, 21, 257-270.

Pascual-Marqui, R. D., Michel, C. M., Lehmann, D. (1994). Low resolution electromagnetic tomography. a new method for localizing electrical activity in the brain. Int J Psychophysiol, 18, 49-65.

Pascual-Marqui, R. D. (1999). Review of methods for solving the EEG inverse problem. IJBEM, 1, 7586.

Pascual-Marqui, R. D. (2002). Functional imaging with low-resolution brain electromagnetic tomography (LORETA): a review. Methods Find Exp Clin Pharmacol, 24 Suppl.C, 91-96.

Pataraia, E., Feucht, M., Lindinger, G., Aull-Watschinger, S., Baumgartner, C. (2008). Combined electroencephalography and magnetoencephalography of interictal spikes in benign rolandic epilepsy of childhood. Clin Neurophysiol, 119, 635-641.

Ponten, S. C., Bartolomei, F., Stam, C. J. (2007). Small-world networks and epilepsy: graph theoretical analysis of intracerebrally recorded mesial temporal lobe seizures. Clin Neurophysiol, 118, 918-927.

Sander, J. W. A. S., Sillanpää, M. (1997).Natural history and prognosis. In J. Engel, \& T. A. Pedley (Eds.), Epilepsy: a comprehensive textbook (pp. 69-86). Philadelphia: Lippincott-Raven Publishers.

Schevon, C. A., Capell, J., Emerson, R., Isler, J., Grieve, P., Goodman, R., Mckahn, G. Jr., Weiner, H., Doyle, W., Kuzniecky, R., Devinsky, O., Gilliam, F. (2007). Cortical abnormalities in epilepsy as revealed by local EEG synchrony. Neurolmage, 35, 140-148.

Schevon, C. A., Goodman, R. R., McKhann, G. Jr., Emerson, R. G. (2010). Propagation of epileptiform activity on a submillimeter scale. J Clin Neurophysiol, 27, 406-411.

Sillanpää, M., Schmidt, D. (2006). Natural history of treated childhood-onset epilepsy: prospective, long-term population-based study. Brain, 129, 617-624.

Smit, D. J., Stam, C. J., Posthuma, D., Boomsma, D. I., de Geus E. J. (2008). Heritability of "smallworld" networks in the brain: a graph theoretical analysis of resting-state EEG functional connectivity. Hum Brain Mapp, 29, 1368-1378. 
Smith, A. B., Kavros, P. M., Clarke, T., Dorta, N. J., Tremont, G., Pal, D. K. (2012). A neurocognitive endophenotype associated with rolandic epilepsy. Epilepsia, 53, 705-711.

Spencer, S. S. (2002). Neural networks in human epilepsy: evidence of and implications for treatment. Epilepsia, 43, 219-227.

Stam, C. J., van Straaten, E. C. (2012). The organization of physiological brain networks. Clin Neurophysiol, 123, 1067-1087.

Strzelczyk, A., Reese, J.P., Dodel, R., Hamer, H.M. (2008). Cost of epilepsy: a systematic review. Pharmacoeconomics, 26, 463-476.

Talairach, J., Tournoux, P. (1988). Co-Planar Stereotaxic Atlas of the Human Brain:Three-Dimensional Proportional System. Stuttgart: Georg Thieme.

Tao, J. X., Baldwin, M., Hawes-Ebersole, S., Ebersole, J. S. (2007). Cortical substrates of scalp EEG epileptiform discharges. J Clin Neurophysiol, 24, 96-100.

Thatcher, R. W., Biver, C. J., North, D. (2007). Spatial-temporal current source correlations and cortical connectivity. Clin EEG Neurosci, 38, 35-48.

Timofeev, I., Steriade, M. (2004). Neocortical seizures: initiation, development and cessation. Neuroscience, 123, 299-336.

Turrigiano, G. G., Nelson, S. B. (2004). Homeostatic plasticity in the developing nervous system. Nat Rev Neurosci, 5, 97-107.

Wendling, F., Ansari-Asl, K., Bartolomei, F., Senhadji, L. (2009). From EEG signals to brain connectivity: a model-based evaluation of interdependence measures. J Neurosci Methods, 183, 9-18.

Wirrel, E. C., Camfield, P. R., Gordon, K. E., Dooley, J. M., Camfield, C. S. (1995). Benign rolandic epilepsy: atypical features are very common. J Child Neurol, 10, 455-458.

Wolf, P., Pastuchova, T., Mataringa, M. (2006). Decline in seizure propensity in seizure-free patients as reflected in the evolution of the therapeutic antiepileptic drug threshold. Epilepsy Behav, 8, 384390.

Zietsch, B. P., Hansen, J. L., Hansell, N. K., Geffen, G. M., Martin, N. G., Wright, M. J. (2007). Common and specific genetic influences on EEG power bands delta, theta, alpha, and beta. Biol Psychol, 75, 154-164. 


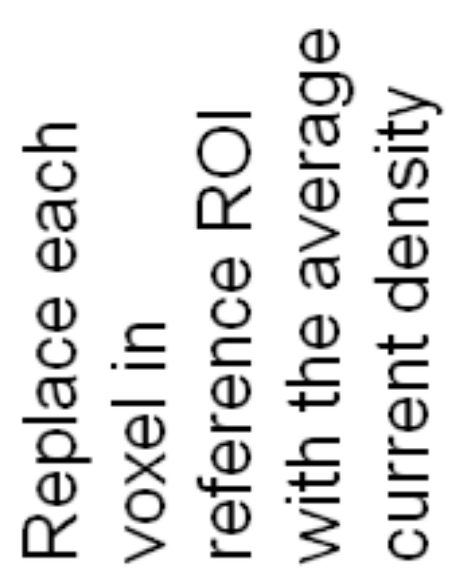

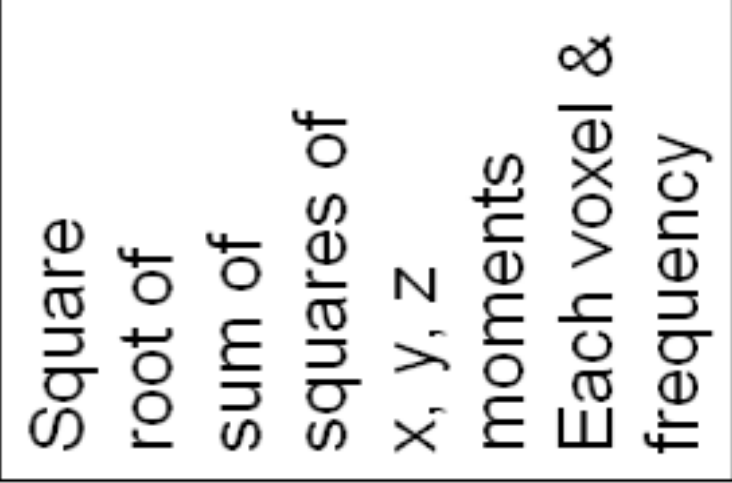
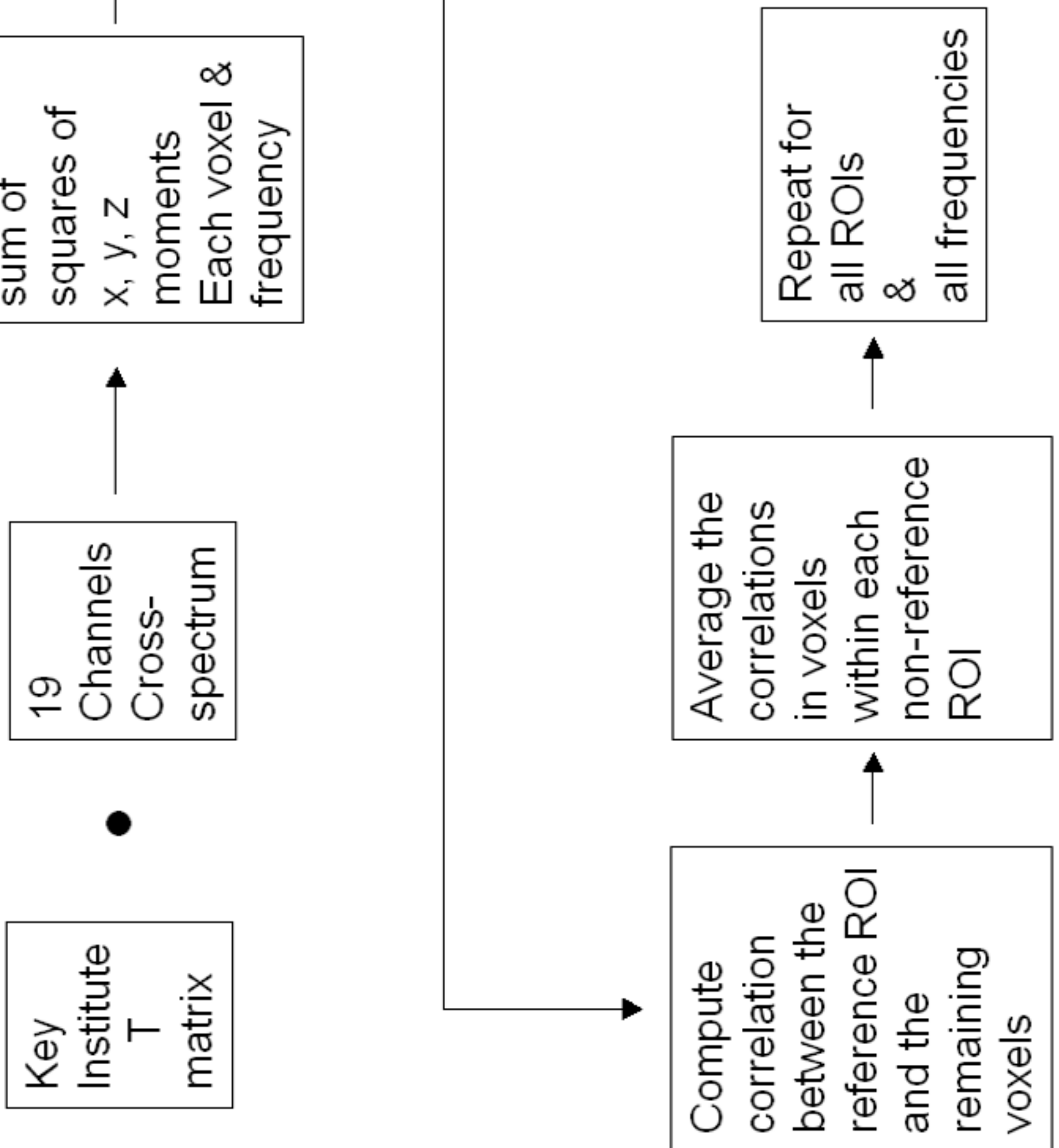


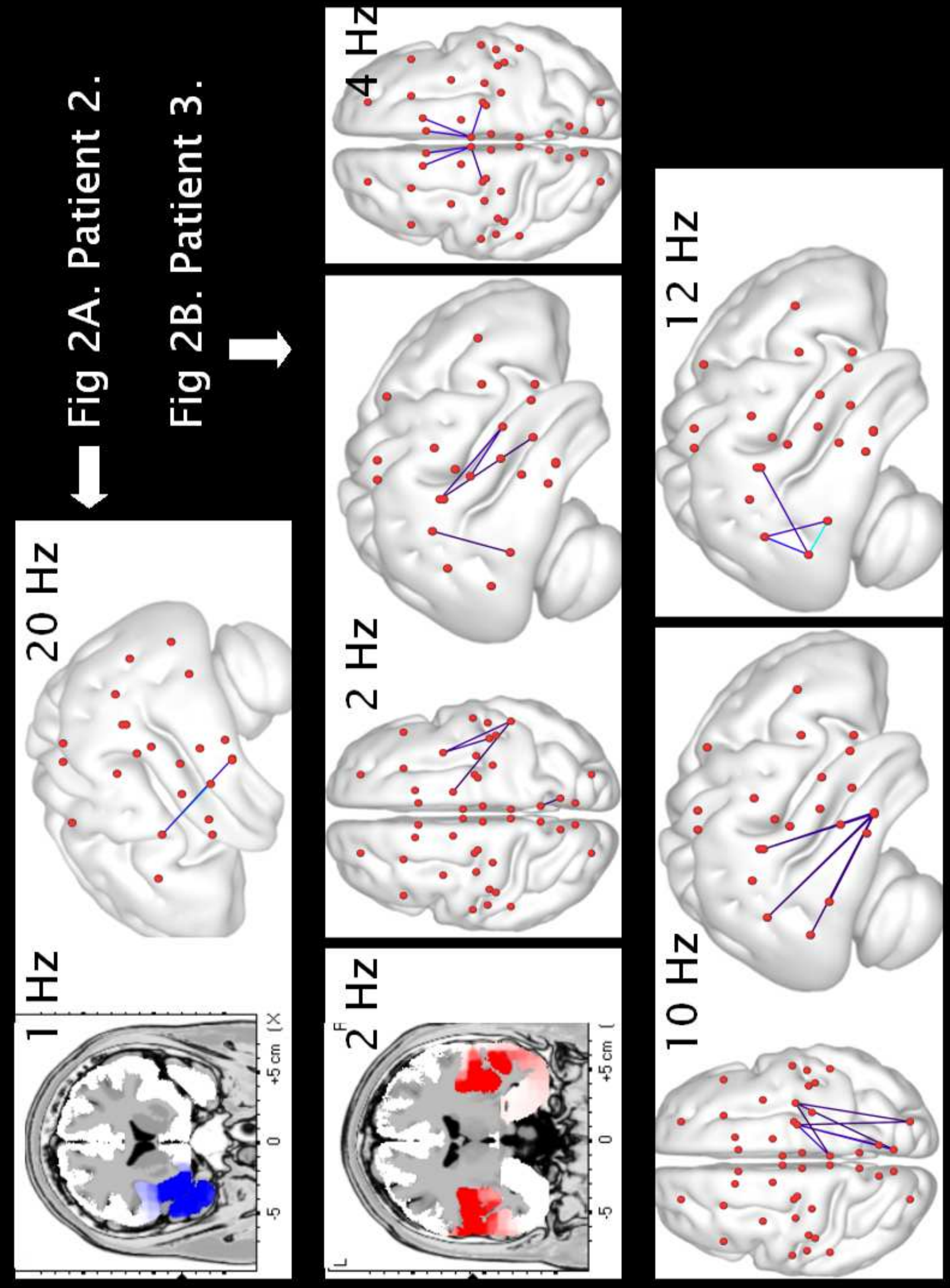




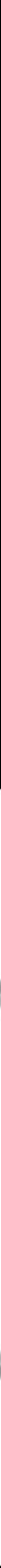




\begin{tabular}{|l|l|l|l|l|l|}
\hline $\begin{array}{l}\text { Patient No. } \\
\text { and sex }\end{array}$ & $\begin{array}{l}\text { Age at } \\
\text { EEG1 }\end{array}$ & $\begin{array}{l}\text { Age at } \\
\text { EEG2 }\end{array}$ & $\begin{array}{l}\text { Cranial } \\
\text { MRI }\end{array}$ & $\begin{array}{l}\text { Seizure symptoms and the number } \\
\text { of seizures }(\mathrm{n}) \text { before diagnosis }\end{array}$ & $\begin{array}{l}\text { Treatment and therapeutic } \\
\text { results }\end{array}$ \\
\hline Pt 1, F & 10.8 & 14.4 & normal & $\begin{array}{l}\text { Speech arrest and tingling of the } \\
\text { left face on awakening (3) }\end{array}$ & $\begin{array}{l}\text { carbamazepine (150 mg } \\
\text { daily), seizure-free }\end{array}$ \\
\hline Pt 2, M & 7.1 & 10.4 & normal & $\begin{array}{l}\text { Oro-pharyngo-laryngeal motor } \\
\text { seizures while asleep (2) }\end{array}$ & $\begin{array}{l}\text { carbamazepine (300 mg } \\
\text { daily), seizure-free }\end{array}$ \\
\hline Pt 3, F & 6.4 & 13.5 & normal & $\begin{array}{l}\text { Right hemifacial sensory seizures, } \\
\text { speech arrest on awakening (2) }\end{array}$ & $\begin{array}{l}\text { carbamazepine (300 mg } \\
\text { daily). Two further seizures, } \\
\text { thereafter seizure-free }\end{array}$ \\
\hline Pt 4, F & 9.5 & 15.5 & normal & $\begin{array}{l}\text { Clonic motor seizures in the head, } \\
\text { speech arrest on awakening (3) }\end{array}$ & $\begin{array}{l}\text { oxcarbazepine (300 mg } \\
\text { daily), seizure free }\end{array}$ \\
\hline
\end{tabular}

Table 1. Main clinical data of the patients 


\begin{tabular}{|l|l|}
\hline Pt 1. & $\begin{array}{l}\text { LORETA1: decreased activity in the } L \text { and } R \text { medial frontal gyri } \\
\text { LSC1: increased EEGfC between the } L \text { cingulate gyrus and the inferior and middle frontal gyri } \\
\text { LORETA2: no abnormality } \\
\text { LSC2: Decreased EEGfC between the R middle frontal and inferior frontal gyri. Increased } \\
\text { EEGfC between the } L \text { cingulate and inferior frontal gyri }\end{array}$ \\
\hline Pt 2. & $\begin{array}{l}\text { LORETA1: decreased activity in the } L \text { inferior frontal gyrus } \\
\text { LSC1: decreased EEGfC between the } L \text { inferior frontal gyrus and the parahippocampal gyrus } \\
\text { and uncus } \\
\text { LORETA2: no abnormal findings } \\
\text { LSC2: no abnormality }\end{array}$ \\
\hline Pt 3. & $\begin{array}{l}\text { LORETA1: increased activity in the } L \text { and R superior, middle temporal gyri, insulae; maximum } \\
\text { score in the } L \text { superior temporal gyrus) } \\
\text { LSC1: decreased EEGfC among multiple ROls in the RH. Bilaterally decreased EEGfC } \\
\text { between the cingulate gyrus and the superior frontal, medial frontal gyri and the paracentral } \\
\text { lobule. Increased EEGfC among the } L \text { superior and middle temporal gyri, uncus, insula }\end{array}$ \\
$\begin{array}{l}\text { LORETA2: no abnormality } \\
\text { LSC2: increased EEGfC among LH and RH ROls }\end{array}$ \\
\hline Pt 4. & $\begin{array}{l}\text { LORETA1: no abnormality } \\
\text { LSC1: decreased EEGfC between the L lingual gyrus and the occipital gyri. } \\
\text { LORETA2: no abnormality } \\
\text { LSC2: Increased EEGfC between the } R \text { orbital-frontal area and the posterior cingulate, cuneus, } \\
\text { lingual gyrus; between the } L \text { posterior cingulate and orbital frontal area. Decreased EEGfC } \\
\text { between the } L \text { and R precuneus and lingual gyrus. }\end{array}$ \\
\hline
\end{tabular}

Table 2. EEG and Z-scored quantitative EEG findings at the onset of epilepsy (index1) and in terminal remission (index2). Localization of the EEG abnormalities is given by abbreviations of the standard electrode positions. Abnormal LORETA and LSC activities are characterized by their sign and topographical extension. 